\title{
Towards an Effective Management on the Teaching and Learning of Accounting in Secondary Schools
}

\author{
Lilian Nwosu* , Andre Bechuke and Pontso Moorosi
}

Academic Lecturer, North West University, School Of Accounting Sciences, 5404 Unit 13 Mmabatho, Mafikeng, South Africa

${ }^{*}$ Corresponding author: Lilian Nwosu, Academic Lecturer, North West University, School Of Accounting Sciences, 5404 Unit 13 Mmabatho, Mafikeng, South Africa, Tel: 0788831073; Fax: +27788831073; E-mail: 23012064@nwu.ac.za

Received Date: March 15, 2018; Accepted Date: March 21, 2018; Published Date: March 25, 2018

Copyright: (c) 2018 , et al. This is an open-access article distributed under the terms of the Creative Commons Attribution License, which permits unrestricted use, distribution, and reproduction in any medium, provided the original author and source are credited.

Citation: Nwosu L, Bechuke A, Moorosi P (2018) Towards an Effective Management on the Teaching and Learning of Accounting in Secondary Schools: Case Report. Br J Res Vol. 5 No. 1: 38.

\section{Abstract}

Object: The aim of the study was to investigate various ways in which the Accounting educators and the School Management Teams (SMTs) manage the teaching and learning of Accounting in secondary schools.

Methodology: A qualitative approach which was modeled on the case study research design was used to find out ways the teaching and learning of accounting are managed in schools. Two schools were selected in Mafikeng area of the North West Province to participate in the study, where interviews and observations were used to collect data. Participants included all the SMTs that contribute to the management of teaching and learning of accounting and consisted of the principal, deputy principal and the accounting HoDs in the two schools. Accounting educators were interviewed and observed while teaching. The data was analyzed and the findings were presented and discussed. The main findings of this study revealed that: there are various number management strategies which were employed by the schools to manage the teaching and learning of accounting. These strategies include; supporting accounting educators, providing teaching and learning of resources to accounting educators and learners, supervising the teaching and learning of accounting in the classroom and providing exchange programs for accounting learners. The study recommends that training; support and action plan approaches should be used by the SMTs, accounting educators and Department of Education (DoE) to manage the teaching and learning of accounting in secondary schools.

Conclusion: The researcher concludes that the study might inform SMTs and accounting educators on the various ways in which they can manage the teaching and learning of accounting.

\section{Keywords:}

School Management

Teams

(SMT);

\section{Introduction}

Accounting has been identified as a priority subject by the Department of Basic Education. The subject encompasses Accounting knowledge, skills and values that focus on financial accounting, managerial accounting and auditing fields, which prepare learners for a variety of career opportunities [1]. However, it is also a subject that has received increased criticism because of the poor performance of learners (Schreuder 2014). This poor performance in accounting concerns accounting educators who do not have adequate knowledge in accounting content and because they are not properly trained and equipped to teach accounting competently $[2,3]$. The Landelani Recruitment Group [4] also identified accounting as one of the subjects in which educators encountered learners with reading problems, arithmetic deficiency and language problems. It is the importance of the subject and the criticisms it has received that prompted this research study. The purpose of this investigation is therefore not in the delivery of the content as such, but on how the accounting educators in schools manage the teaching and learning of accounting as a subject.

Accounting is offered as a subject in both public and private schools in South African high schools, in the learning area of Economic and Management Science (EMS). This EMS learning area is combined with Economics and Business Studies which can also be referred to as the commerce cluster subjects. Accounting, as a subject in its own right, starts getting fully taught from Grade 10 to12 in the Further Education and Training (FET) phase [5]. Accounting educator was able to make sense of the teaching and learning of accounting before the introduction of the new curriculum. Even though most accounting educator struggles with the content and teaching style to be implement, they still manage to teach the learners effectively. According to Rajoo, when the new accounting FET curriculum was implemented in Grade 10 in 2006, educators had to make sense of a new curriculum with little support from the Department of Education (DoE). Apart from a week of training conducted by facilitators who were not familiar with the new curriculum themselves, it was left to internal school Heads of Department (HoDs) to orientate educators within the accounting departments [5]. The new curriculum had additional topics and 
new assessment strategies as such the accounting educators had to orientate themselves with, let alone the teaching content.

School Management Teams provide leadership and support for teaching and learning in South African schools. These teams comprise all educators with management roles within the school - the principal, deputy principal(s) and Heads of Department (HoDs). When the SMT is working well, it provides good potential for generating and sustaining high quality teaching and learning [6]. Furthermore, it is observed that SMTs have a vital role to play helping educators to become competent and in transforming schools into centers of excellence. This is because SMTs have to work collaboratively with educators to come up with various strategies that would ensure the provision of quality education. The quality of effective teaching and learning provided by the school and levels of achievement greatly depend on the roles played by the SMTs as well as other stakeholders of the school in general. Within the SMT, the principal has a very distinct role in leading learning or providing instructional leadership. Bush, Joubert, Kiggundu and Van Rooyen [7] suggest that;

"The core purpose of principalship is to provide leadership and management in all areas of the school to enable the creation and support of conditions under which high quality teaching and learning take place and which promote the highest possible standards of learner achievement."

Bush \& Glover [8] conclude that where SMTs operate successfully, they have great potential to improve classroom practice and the educator's management skills in teaching and learning. This happens mainly through HoDs sharing their ideas, developing school-wide policies and enacting consistent practice throughout the school. According to Rajoo [5] SMTs spend much time in supervising the teaching and learning activities that occur daily in their subject. The SMTs also ensure that teaching and learning in schools are carried out effectively by providing the necessary support for the Accounting educators as well as continuous monitoring of the support strategies provided for the Accounting educators in schools. Colvin [9] affirms that the critical role played by SMT in instructional leadership creates the kind of environment necessary for school change and for the improvement plans to be effectively implemented

The study therefore sought to investigate how the teaching and learning of Accounting is managed by the SMTs and Accounting educators in secondary schools. To facilitate this investigation, the study asked the following questions:

In what ways are the teaching and learning of accounting managed by SMTs in secondary schools?

\section{Instructional Leadership}

The study used instructional leadership theory to guide the literature review and explain the findings. Bush [8] identified different educational leadership and management models that have been used to explain practices of managers in schools for decades. From these, instructional leadership was deemed appropriate and most relevant to explain SMTs practices and strategies in supporting teaching and learning. The international literature mainly refers to the "leadership" of teaching and learning as "leadership for learning" or "instructional leadership", while in South Africa it is simply referred to as the leadership and management of teaching and learning [7]. The study draws from the international literature using these different concepts but instructional leadership is retained as a concept for consistency.

Rajoo [5] defines instructional leadership as providing direction, resources and support to educators and learners with the aim of improving and ensuring a sound culture of teaching and learning at all times. Instructional leadership involves setting clear goals, managing the curriculum, monitoring lesson plans, allocating resources and evaluating educators regularly to promote growth of learning [10]. It also involves setting direction and providing high quality instruction in all settings [11]. Instructional leadership requires SMT members to wear many hats of being administrators, managers, diplomats, educators and curriculum leaders [10]. Instructional leadership focuses on strategic school-wide actions that are directed towards school improvement and shared among the principal, educators, administrators and others. Leadership also entails the use of governance structures and organizational processes that empower staff and learners encourage broad participation in decision making, and foster shared accountability for learners learning [12].

The quality of relationships that educators develop with learners is a critical factor in instructional leadership [13]. According to Masuku [14] learners tend to appreciate educators who take a personal interest in them and their development. Positive relationships between educators and their learners are crucial in that they enable educators to develop trust between themselves and learners, shaping learners' attitudes towards their school work [13] affirms that educational values focus on how educators, learners and SMTs should interact to promote learning and sustain order. These values therefore require instructional leaders in school to provide instructional support, from goal setting to educators' support and mentoring; assessment expertise; and professional development on topics in the various areas of expertise for the followers. Bush \& Middlewood [15] submit that instructional leadership theory is significant because it targets the main purpose of educational organizations, which is teaching and learning (of Accounting in schools in the case of this study). Instructional leadership has also become an increasingly important aspect of reforming and improving schools [16]. The use thereof helps to improve the teaching and learning of Accounting in schools by reforming the Accounting educators' SMTs through various instructional leadership models in school management.

Table 1 illustrates the model of instructional leadership which can be used by SMTs and accounting educators in managing teaching and learning of accounting in secondary schools [1].

Different authors have presented different models of instructional leadership which are useful for describing the SMTs role in promoting teaching and learning. According to Masuku [14] a model is roadmap to success. The models of instructional leadership are also essential because they provide a broad framework for the high school heads in creating a culture of 
teaching and learning (COTL) in schools [14]. These models enable the SMTs to know what is expected of them in order to ensure effective teaching and learning in South African secondary schools. According to the model of instructional leadership provided by the Department of Basic Education [1], the SMTs as leaders are expected to set up staff development programs which would assist the Accounting educators.

Table 1 Models of instructional leaderships.

\begin{tabular}{|l|}
\hline Department of Education (2010:10) \\
\hline Setting up staff development \\
\hline Programs \\
\hline Visiting classes and follow-up \\
\hline Discussions \\
\hline Looking at students' work \\
\hline Assisting educators with lesson planning \\
\hline Discussing learners' academic progress with educators \\
\hline Moderating tests and examinations \\
\hline Inducting new educators at school \\
\hline
\end{tabular}

The accounting HoDs as part of the SMTs are expected to visit the classes, monitor the progress of learners, discuss the progress with the Accounting educators, and assist the accounting educator in lesson preparation. This should be done by providing the necessary media for effective teaching and learning to take place in the classroom, moderate the tests that the accounting educator administer to the Accounting learners as well as inducting new accounting educators to teach Accounting when the capacity of learners taking accounting in a specific school is higher than expected. These practices aim to improve learner achievement by creating an environment in which both educators and learners share a clear purpose, are able to take shared responsibility for learning, and are able to engage collaboratively in activities which promote the goals of the school [1]. This model is also a paradigm which recognizes SMTs as instructional leaders as they are liable for taking the lead in putting their school curriculum into practice and improving it [1]. The model would also assist SMTs in generating enthusiasm and expertise in the new curriculum [17]. The model presented above is not distinct from the actions taken by SMTs as instructional leaders to enhance effective teaching and learning of Accounting in secondary schools.

\section{Support for teaching and learning of Accounting}

Prior to the implementation of the National Curriculum Statement (NCS) in the Further Education and Training (FET) band (Grades 10-12); Accounting was regarded as the art of recording transactions [5]. This heavy focus on financial accounting recording and reporting influenced educators to use a procedural approach as a point of departure in the teaching and learning of the subject. As a result, many educators regarded knowledge of the recording or bookkeeping process as a major outcome for Accounting as a subject [6]. This observation implies that the traditional format for the teaching of Accounting was too narrow, too procedural and too mechanical, and forced the learners to rely on memory only [18]. Ngwenya [19] affirms that learners' reasoning abilities and the practice of reflecting on the financial information through solving problems were hardly ever addressed or assessed in the old accounting curriculum. This brought about the changes in the Accounting curriculum in 2005 . New content was included in the curriculum, which was aimed to restructure the old and new topics in the syllabus and add in new ways of facilitating learners' learning. The problem facing accounting educators as well as the SMTs is to adopt a way to change their teaching and assessment practices and to align them with the requirements of the new curriculum in order to enable effective management of teaching and learning of accounting in secondary schools.

In respect of support for Accounting educators and SMTs, Dombroski, Garner, Kenneth, Marshall \& Smith [20] suggest that the accounting curriculum must be structured in such a way that it develops one's ability to teach accounting effectively. According to them, educators as instructional leaders should be involved in developing the accounting curriculum and managing the teaching and learning of accounting because they are the ones who are faced with the challenges of implementation, and they also understand how the learners learn better. Hoadley \& Ward [21] argue that the whole process of developing and implementing the curriculum was rushed, which inevitably resulted in problems in implementation. Educators felt trapped into trying to make sense of all the new terminology in the curriculum. So some educators did not even attempt to implement the curriculum and others carried on teaching like they used to prior to the curriculum change. Accounting educators can therefore reduce anxiety for themselves and their accounting learners by becoming more familiar with the course material and incorporating new methods for teaching accounting Buckhaults \& Fisher, et al. Buckhaults \& Fisher also affirm that for the teaching and learning of Accounting to be effective, educators have to come to class well-prepared and fully understanding the material to be presented, then they will be able to introduce new methods, theories and philosophies into accounting education to ensure that learners view accounting as an interesting subject in which they will enroll and succeed.

The DoE [22] sees support programs as structured interventions delivered at schools and in classrooms within specific time frames. They also highlighted Support delivery can be optimally efficient and cost-effective if it is based on intersectional collaboration among the schools as well as the department of education. Support provision can be provided along a continuum of intensity ranging from low to moderate to high. This will depend on the intellectual capability of the learners in the classroom.

Five specific support provision areas are identified were identified by the DoE:

- The availability of specialist support staff which will support Accounting educators in teaching Accounting; 
- The availability of assistive devices, specialized equipment and teaching and learning support materials (LTSM);

- The extent to which the Accounting curriculum is differentiated to meet the individual needs of learners and

- The delivery of initial and on-going training, orientation, mentorship and guidance for accounting educators in schools.

It is therefore important for SMTs to ensure that these support provisions are provided for the Accounting educators in order to enhance effective teaching and learning of Accounting in the schools in order to positively impact on the success of learners.

\section{Methodology}

A qualitative research approach was used in this study. Qualitative research was viewed as the best approach for this research because it provides the researcher with an opportunity to understand the management of teaching and learning of Accounting in schools in its natural setting. In a natural setting, a researcher addresses the process of interaction among individuals focusing on the specific contexts in which people live and work [23]. Qualitative data is important because most of the descriptions and interpretations of data in this study are rendered in words rather than numbers. Qualitative research also provides the researcher with an opportunity to understand the social phenomenon from the participants' perspective. This was done by analyzing the contexts of the participants from the case study research design and by narrating participants' meanings which included their feelings, beliefs, ideas, thoughts and actions [24].

There are 36 secondary schools in Mafikeng Area Office, 20 of these schools offer accounting as a subject. Since all the schools offering Accounting as a subject could not be used, a purposeful sample was used to select only 2 schools from the 20 secondary schools offering Accounting as a subject. Buckingham $D$ refer to purposive sampling as a non-probability sampling method which involves purposive or deliberate selection of particular site or participants from a sample relevant to the study [25]

The participant selected from the two schools can be seen in Figure 1.

From the 2 secondary schools that were selected, all participants involved in the management of teaching and learning of Accounting were interviewed. This implies that the participants that were used in this study for each school have no selection criteria. This was because they were responsible for the didactics and management of the accounting discipline. The participants that are involved in the management of teaching and learning as in the case of this study include the SMTs and the accounting educators. Thus, the principal, deputy principal, accounting HoDs and accounting educators in the school were all interviewed. As such, a total number of 9 participants were used for the study as presented in the figure above.

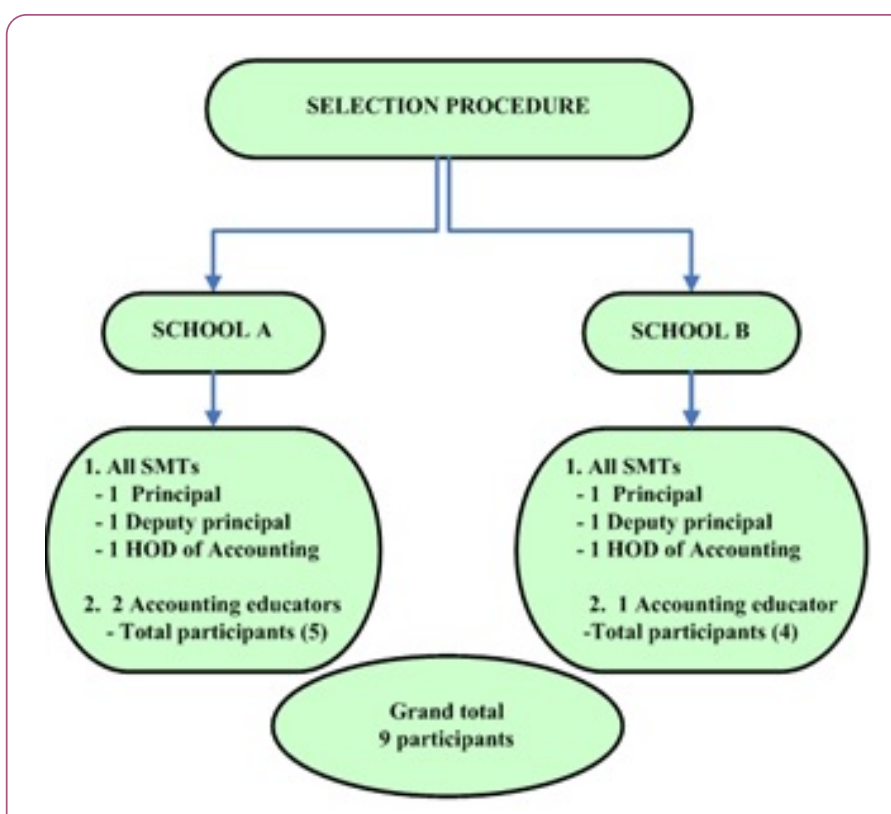

Figure 1 Participant selection.

\section{Findings and Discussions}

Findings from interviews made with the participants in this article in school A and B reveal that the SMTs and the accounting educators used various ways to manage the teaching and learning of Accounting. Findings in respect to this revealed that the SMTs play a major role in the management of teaching and learning of accounting by monitoring the progress of the Accounting educators, supervising the teaching and learning of accounting in the classrooms, supporting the Accounting educators in teaching and learning and conducting an exchange programme with schools which offer accounting.

\section{Monitoring the Progress of Accounting Learners and Accounting Educators in Schools}

\section{In school A}

The principal identified that the important role that the SMTs play in respect of managing teaching and learning of Accounting is that they monitor the progress of the accounting educators and learners. This is done by ensuring that the accounting educators are up to date with their teachings. The accounting educator in this school affirms that the principal always request for the progress report of the learners in the class and this was always a normal check-up routine for the school.

\section{In school B}

The principal stated thus:

"Basically we have the role to monitor the progress of the accounting educators as well as the accounting learners by ensuring that the accounting educators teach the learners well. 
This is so because we want the Accounting educators to have the desire to teach and not absenting herself in schools with one reason or the other. For learners we monitor their progress also and give feedback to them that will help to understand and accomplish their work."

In addition to the principal's views in respect of the roles of SMTs in managing teaching and learning of accounting, the deputy principal indicated thus:

As members of the SMTs we do engage the HoD on the basis of teaching and learning accounting... that is, we encourage them as well as ask them to report every weekly on the successfulness of accounting teaching for that week. This method enables us to keep on track with their progress.

The accounting educator in this school also confirmed that the SMT ensures that the progress of the learners are monitored, recorded and maintained in each term to ensure effective management of the teaching and learning of Accounting.

From the findings, it is evident that the SMTs manage teaching and learning of accounting by monitoring the progress of the accounting educators in the schools. For instance, the statements of the accounting HoD and principal in both schools demonstrate that the SMTs ensure that learners are up to date with the contents, homework, test and exams. According to them they ensure that the performance of learners is captured and reported to the parents accordingly. To confirm this, accounting educator 1 in school B confirms that the SMT ensures that the progress of the learners are monitored, recorded and maintained in each term to ensure effective management of the teaching and learning of Accounting. In addition, the models of instructional leadership presented in DoE [1] also indicated that SMTs are required to monitor and discuss the learner's academic progress with accounting educators. Ntseto [10] also supports those SMTs as instructional leaders are expected to monitor the progress of educators in schools. Therefore, by implication it is evident that one of the roles played by the SMTs in managing teaching and learning of Accounting is through constant monitoring of the progress of the accounting learners in the school.

\section{Supervising the teaching and learning of accounting in the classroom}

This was also another point that was highlighted by the HoDs that were interviewed in both schools.

\section{In school A}

The accounting HoD stated thus:

"Basically I am the HoD for Accounting, Economics and Business studies I help them in their classrooms to teach the subject in the area where I can and support them in difficulties. By difficulties I mean helping these educators in using assessment techniques, how to maintain records of accounting learners' progress, and how to set themselves targets."
The accounting HoD also stated that during classroom visits she looked at the learners work checked whether it was marked and also listened to how educators interact with learners.

In addition, the principal also indicated that they have a dedicated group of HoDs that always put the learners' interest first and they reflect a commitment to teaching and learning. They have the ability to drive things along and maintain a good balance of pressure and support. In general, according to her, the accounting HoD in the school is somewhat knowledgeable about the subjects and always strives to teach the subject on topics she has basic knowledge on.

\section{In school B}

Contrary to what was found in school $A$, the accounting HoD in school B indicated that the accounting educator in most cases refused to be supervised in the classroom but rather through her works done as captured in her files. According to her she only supervised the file so as to find out if the learners are up to date with their studies and never bothers to teach the learners due to lack of knowledge in accounting as presented earlier.

The findings therefore reviewed that the HoD interviewed in school A accepted that she assists the Accounting educator in her school by sometimes going to teach in the classroom. She explains that such assistance was usually provided once it is needed to get the educator and learners out of difficulties of using assessment techniques, how to maintain records of learners' progress and set targets. From her explanation, the inference is that apart from being a HoD in other subjects she mentioned, as her primary assignment, she overlaps this by playing the role of an educator to ensure effective teaching and learning of accounting in her school. She also does the work of supervision and gets feedback from students by interacting with them particularly with regards to educator-learner relationship.

The principal of the same school intimates that the Accounting HoD supervises Accounting educators while teaching in the classroom to ensure effective teaching of learners by their Accounting educators. However, she maintains that this is one of the duties of her Accounting HoD. Evidence of the supervision of teaching and learning of accounting in the accounting classroom was obtained from the observations made. This demonstrates that the school undertakes to collectively ensure that teaching and learning of accounting in the school improves. In other words, there is a synergy of efforts between the accounting educator, HoD and principal of the school to enhance the teaching and learning of the subject. It also demonstrates that the model of instructional leadership in DoE [1] in respect of HoDs visiting the classroom and supervising the teaching and learning is attained.

The situation in school B is in contrast with school A. The accounting HoD indicated that she does not supervise the teaching and learning of accounting in the classroom because the accounting educator in most cases refuses to be supervised; as such she only supervises the files to ensure that the teaching and learning is up to date. From her explanation, the inference from this is that the lack of supervision by the HoD in school B can reduce the effective teaching and learning. This is because if 
the Accounting educator refuses to be supervised it either implies that she might not be knowledgeable of the subject or she is not comfortable with the presence of the accounting HoD. This also implies that the model of instructional leadership is not attained.

\section{Supporting the Accounting Educators}

Support is a vital role in an education system. This implies that Accounting educators (as in the focus of this study) need to be supported in various ways in order to teach accounting effectively. During the interview process the SMTs mentioned support as a role which they play in managing teaching and learning of Accounting in schools.

\section{In school A}

The principal commented thus:

"I give the accounting educators and accounting HoDs support; I make sure that whatever is in my reach I try by all means to provide. Sometimes I call the parents of the learners offering accounting just to tell them the importance of accounting and importance of constant practicing. This is the support I usually give them on my own as a principal."

\section{In school B}

The deputy principal indicated that:

"We try as much as we can as managers of the school to provide the necessary support to accounting educators and Accounting HoDs at all times in order to foster effective teaching and learning of Accounting."

This implies that the principals as part of the SMTs play a vital role in supporting the Accounting educators in order to enhance effective teaching and learning of Accounting.

Because of the fact that any form of support is vital to encourage teaching, providing such support becomes imperative for accounting educators to function optimally, effectively and efficiently in schools. The principal in school A observes that supporting accounting educators is fundamental to the effective teaching and learning of the subject. As a consequence, she provides educators with whatever assistance or support they may need, provided powers to do so lies within her power as the principal. To the principal, accounting is an important subject and this fact had necessitated her resolve to interact with parents to encourage their children to offer the subject. From her perspective, this interaction is her small way of promoting the subject as well as to support the teaching and learning of accounting in her school.

Similarly, the HoDs within their capacity equally provide such support to accounting educators. The accounting HoD and principal in school B were quick to state in this regard that providing necessary support to accounting educators is continuous and vital for the effective teaching and learning of the subject. In other words, school B consistently provides fundamental assistance to the accounting educator in the school. By implication, it means that providing support to
Accounting educators is seen as important in both schools and ensuring it is done is even more important. It also shows that such support is provided in both schools to encourage effecting and ensuring a conducive atmosphere of teaching and learning of accounting in their schools.

The DoE [1] indicated that the SMTs have the responsibility to provide the necessary support to the accounting educators that would enable them to foster effective teaching and learning. The need for SMTs support to accounting educators was also stressed by Bush, et al. [7]. To buttress this point, the roles of instructional leaders indicated that SMTs as instructional leaders are expected to support the accounting educator in teaching. The point of this discussion illustrates that the SMTs in both schools act as instructional leaders and are dedicated in ensuring that the Accounting educators gets the necessary support that would help in effective teaching and learning of Accounting.

\section{Exchange Programme}

Exchange programme between accounting educators from outside the school were also identified by the participants as a way of managing teaching and learning of Accounting in schools.

\section{In school A}

The Accounting educator 1 stated thus:

"One of the ways we manage effective teaching and learning of Accounting in schools is to invite other Accounting educators from other schools to come and teach our learners while we also go and teach their own learners so that our learners will acquire more knowledge from other educators."

Accounting Educator 2 also indicated that sometimes the school invites past accounting learners who have made it in accounting with a good mark to come and teach the learners or expand their knowledge on how they made it in respect to Accounting.

\section{In school B}

The accounting educator also indicated that they run an exchange programme with other Accounting educators. Most of the time the accounting learners as well as other Accounting learners from other schools go on accounting conference training, where knowledgeable accounting educators will teach them topics so they can understand. According to her, this method helps to manage effective teaching and learning of accounting in the school. Even though their percentage pass rate in accounting is still at $60-70 \%$ she believes that as time goes on and as more ways to manage teaching and learning are found the school would improve its percentage pass rate.

However, exchange programs for accounting educators proved to be a better way to effectively manage teaching and learning of accounting in secondary schools. According to the International Teachers Exchange Services (ITES) [26] educators are dedicated in building friendship and cultural understanding through exchanges. The educators are tasked with preparing the 
learners of today to be ready to compete in the global workplace, and that cross-cultural interaction creates an effective and dynamic learning environment.

The improvement in percentage pass indicated by participants from both school is a confirmation in this regard. The simple inference here is that the exchange programme is an effective method of managing the teaching and learning of accounting in secondary schools. The statement of educator 1 in school A clearly shows that the exchange program has proved to be effective. The accounting educator reveals that inviting accounting educators from other secondary schools is among the strategies they adopt to improve the teaching and learning of the subject across secondary schools. While accounting educator 2 in the same school agrees with this assertion, he went further to mention that they also invite past intelligent accounting learners to provide teaching support to accounting learners also as part of the school's strategy.

In school B, the accounting educator indicated that the school runs exchange programs as well. To this end, the statement of the educator reveals that they also make use of the strategy of exchange program to ensure efficient management of teaching and learning of accounting in the school. She also mentioned that this method will give the school an increased pass rate. Exchanging accounting educators from one school to another in order to teach accounting learners and inviting past intelligent accounting learners who have achieved distinctions in accounting to come and teach the accounting learners are a good indication that effective teaching and learning of accounting can take place, hence, improving learners' performance in accounting.

\section{Providing Extra Accounting Resource}

\section{In school A}

\section{Accounting educator 1 stated thus;}

"Accounting resource is a key to good Accounting pass rate. Without resources or support to teach accounting to learners, teaching and learning of accounting would not be effective. Therefore it is important that funds be provided by the department to the school so that they can utilize it in buying those electronic Medias that are required to teach accounting effectively."

\section{In school B}

The accounting educator indicated that for effective teaching and learning of Accounting to be properly managed, the DoE should provide extra resources that have been indicated earlier (apart from the well-known text books) for the Accounting educators to teach Accounting effectively.

Therefore, effective management of teaching and learning of accounting hangs on the provision of extra resources such as digital and electronic gazettes in schools. The accounting educator in school B believes that such resources would make teaching and learning of accounting easier, faster and more effective. Agreeing with the idea, the accounting educators in school A however raises the issue of more funding to secondary schools as key to the development of effective management, teaching as well as learning of the subject in the schools. They argued that such funds will enable school to acquire such electronic devices to provide teaching support needed to enhance teaching and learning of the subject. In the strict sense, the views expressed by participants from both schools indicate the lack of accounting electronic teaching aids or support devices in their schools. It also indicates that lack of such devices implies that it exerts pressure on the effective management of teaching and learning of accounting in their schools. The model of instructional leadership also requires the SMTs to provide enough accounting resources for the educators and the learners [1]. These resources include the use of electronic medias and accounting spreadsheets in teaching accounting. Therefore, the adequacy of teaching and learning materials will enhance the effective management of teaching and learning of accounting.

\section{Recommendation}

The study recommends that the Training, Support and Action (TSA) plan approach should be used to by SMTs and Accounting educators to manage effective teaching and learning of Accounting in secondary schools.

Training is the first provision that should be provided. Training should focus on the accounting educators and learners as well as the HoDs of accounting. During the training the content of accounting should be considered, the strength and weakness of learners should also be addressed. The use of professional accountants during training is also necessary and issues relating to professional development should be emphasized to accounting educators and HoDs.

Support on the other hand is the next provision that should be made in order to effectively manage the teaching and learning of Accounting. In this aspect, SMTs must ensure that accounting educators have the digital facilities and LTSM that would enable them to teach accounting effectively. The SMTs should ensure that they employ more Accounting educators that would support in the teaching and learning of Accounting and professionals should be used in teaching accounting during the exchange programs.

Finally, an Action Plan approach should be used to follow up the teaching and learning of accounting. Here SMTs must ensure that accounting educators use varieties of teaching methods, master the content of accounting and spends more time in teaching rather than chalkboard writing. By so doing, an effective management on the teaching and learning of accounting would be maintained in secondary schools.

\section{Conclusion}

This study was aimed at identifying and discussing the ways in which the SMTs and accounting educators are managing the teaching and learning of accounting in secondary schools. Findings from the interviews made with the relevant participants for the study was presented and discussed with relevant literatures. It was found that various management on 
the teaching and learning of accounting were utilized by the SMTs and accounting educators. These include; the supervision of the teaching and learning of accounting, providing exchange programs, supporting the accounting educators, providing teaching resources and monitoring the progress of the accounting learners. The researcher recommended a TSA approach that can also be utilized by schools to manage the teaching and learning of Accounting in secondary schools.

\section{References}

1. Department of Education (2010) Whole school evaluation: Evaluation guidelines and criteria. September, Pretoria: Government Printer.

2. Letshwene MJ (2014)Improving grade 10 accounting teachers competencies in the Ekurhuleni District of the Gauteng ProvinceMaster's dissertation: University of KwaZulu Natal.

3. Ozden M (2008) The effect of content knowledge on pedagogical content knowledge: the case of teaching phases of matters. Educational Sciences: Theory \& Practice 8: 633-645.

4. Landelahni Recruitment Group (2010) Fast Facts: Financial services short report.

5. Rajoo T (2012) An investigation into the role of the Head of Department (HoD) as an instructional leader in the leadership and management of the teaching \& learning of Accounting in two secondary schools in one district in Gauteng. Doctoral dissertation, University of Witwatersrand.

6. Department of Education (DoE) (2008) Subject Assessment Guidelines: Accounting Grades 10-12 (General). Pretoria: Government Printer.

7. Bush T, Joubert R, Kiggundu E, Van Rooyen J (2010) Managing teaching and learning in South African schools. International Journal of Educational Development, 30:162-168.

8. Bush T (2008) Leadership and management development in education. California: Sage Publications.

9. Colvin G (2007) A Guide for Principals and Leadership Teams. United States of America: Corwin Press.

10. Ntseto RM (2015) The role of school management teams (SMTs) in rendering learning support in public primary schools. M.Ed. Dissertation, Bloemfontein: University of Free State.

11. Waldron NJ, McLeskey R, Redd L (2011) Setting the Direction of the Principal in Developing an Effective Inclusive School. Wales.
Welsh Assembly, Cardiff Journal of Special Education Leadership 24: 51-60.

12. Hallinger $\mathrm{P}$, Heck RH (2010) Collaborative leadership and schoo improvement: Understanding the impact on school capacity and student learning. School leadership and management 30: 95-110.

13. Busher H (2006) Understanding educational leadership: people, power and culture. Berkshire: Open University Press.

14. Masuku S (2011) The instructional leadership role of the high school head in creating a culture of teaching and learning in Zimbabwe. Doctoral dissertation, University of South Africa.

15. Bush T, Middlewood D (2013) Leading and managing people in education. (3rd edition). London: Sage.

16. Hoy WK, Miskel I (2005) Educational administration: theory, research and practice. New York: McGraw-Hill.

17. Masekoameng MC, Zengele T (2015) Distributed Leadership in Schools: Enhancing Diverse Leadership Qualities for Success. Pretoria: Van Schaik.

18. Duff A, McKinstry S (2007) Students' Approaches to Learning. Issues in Accounting Education Journal of Accounting Education (Fall). 22: 83-214.

19. Ngwenya JC (2014) Accounting Teachers' Understandings and Practices of Teaching and Assessment in a Context of Curriculum Change. Pretoria: Van Schaik.

20. Dombroski D, Garner R, Kenneth J, Marshall P, Smith M (2010) The accounting education gap, CPA Journal 80: 6-10.

21. Hoadley U, Ward CL (2008) Managing to learn - Leadership of curriculum and instruction in South African secondary schools. Cape Town: HSRC Press.

22. Department of Basic Education (2009) National curriculum statement: national policy on assessment and qualifications for schools in the general education and training band. 1-40. Pretoria: Government Printers.

23. Coetzee JP (2009) Addressing low matriculation pass rates in the Eastern Cape Province: an education management perspective. Doctoral dissertation. University of Eastern cape.

24. Lunenburg, FC (2010) The principal and the school: What do principals do. In National Forum of Educational Administration and Supervision Journal 27:1-13.

25. Buckingham D (2013) Media education: Literacy, learning and contemporary culture. John Wiley \& Sons.

26. International Teachers Exchange Service (2016). 